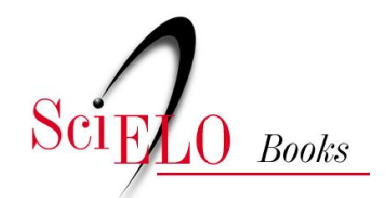

\title{
A importância geopolítica da Bolívia e a integração da América do Sul
}

\author{
Luciano Wexell Severo
}

SciELO Books / SciELO Livros / SciELO Libros

SEVERO, LW. A importância geopolítica da Bolívia e a integração da América do Sul. In

OLIVEIRA, RP., NOGUEIRA, SG., and MELO, FR., orgs. América Andina: integração regional, segurança e outros olhares [online]. Campina Grande: EDUEPB, 2012. pp. 137-159. ISBN 978-857879-185-8. Available from SciELO Books <http://books.scielo.org>.

\section{(c) (1) (2)(2)}

All the contents of this work, except where otherwise noted, is licensed under a Creative Commons Attribution-Non Commercial-ShareAlike 3.0 Unported.

Todo o conteúdo deste trabalho, exceto quando houver ressalva, é publicado sob a licença Creative Commons Atribuição Uso Não Comercial - Partilha nos Mesmos Termos 3.0 Não adaptada.

Todo el contenido de esta obra, excepto donde se indique lo contrario, está bajo licencia de la licencia Creative Commons Reconocimento-NoComercial-CompartirIgual 3.0 Unported. 


\title{
A importância geopolítica da Bolívia e a integração da América do Sul
}

\author{
Luciano Wexell Severo
}

\section{Resumo}

O objetivo deste artigo é realizar uma breve análise sobre a importância geopolítica da Bolívia no cenário da América do Sul, a partir da ótica de destacados pensadores de diferentes nacionalidades. Inicialmente será apresentada uma visão geral do conceito de Heartland, desenvolvido no início do século passado pelo geógrafo inglês Halford Mackinder. A seguir, serão apresentadas as contribuições de autores como o brasileiro Mario Travassos, o estadunidense Lewis Tambs, o brasileiro Golbery do Couto e Silva, o chileno Augusto Pinochet e os bolivianos Jaime Mendoza, Alipio Valencia Vega, Alberto Ostria Gutierrez, Guillermo Francovich e Valentin Abecia Baldivieso, entre outros. Por fim, é sugerida uma releitura do papel da Bolívia no atual processo de integração regional, frente à recente diversificação das atividades econômicas, ao fortalecimento de novas cidades e à aplicação da iniciativa para a Integração de Infraestrutura Sul-Americana (IIRSA). 


\section{Abstract}

The aim of this paper is to present a brief analysis of the geopolitical importance of Bolivia in South American landscape, from the perspective of prominent thinkers of different nationalities. Initially it will be an overview of the concept of Heartland, developed at the beginning of last century by English geographer Halford Mackinder. Below, we present the contributions of authors such as Mario Travassos, Lewis Tambs, Golbery do Couto e Silva, Augusto Pinochet and the Bolivians Jaime Mendoza, Alipio Valencia Vega, Alberto Ostria Gutierrez, Guillermo Francovich and Valentin Abecia Baldivieso, among others. Finally, we suggest a reinterpretation of the current role of Bolivia in the regional integration process due to the recent diversification of economic activities, the strengthening of new cities and the implementation of the Initiative for Infrastructure Integration of South America (IIRSA).

\section{Heartland de Mackinder}

Em 1904, o geógrafo inglês Halford Mackinder apresentou para a Real Sociedade Geográfica de Londres o seu artigo The Geographical Pivot of History. No reconhecido trabalho, estava presente a sua teoria sobre a "área pivô". Em 1919, reapresentou a elaboração com o nome de Heartland (MELLO, 1999, p.45). Segundo a sua interpretação, o mundo estaria dividido em três zonas: o Grande Oceano (que abrange três quartos do planeta), a Ilha Mundial (Europa, Ásia e África) e as ilhas-continentes menores (Austrália e América). 
A grande área continental, cujo centro estava afastado dos mares, tinha características geográficas de uma fortaleza natural rodeada por grandes acidentes geográficos, como rios, desertos, geleiras, planaltos e cadeias montanhosas. Além disso, essa região oferecia a possibilidade de fácil projeção em diversas direções. Tinha poder de articulação territorial e estava posicionada no centro de uma grande massa continental (PFRIMER; ROSEIRA, 2009, p.5). De acordo com Oliveira e Garcia (2010), o conceito de Heartland

Foi desenvolvido para categorizar uma vasta região no "coração da Eurásia", o maior de todos os continentes da Terra, ou "Ilha-Mundo"... O Heartland foi definido originalmente como um vasto território, com amplo potencial para a agricultura, pecuária, extrativismo ou assentamento de grupos humanos. Rica em recursos naturais de toda sorte, além de terras férteis ou potencialmente agricultáveis, reservas de recursos hídricos, planícies, estepes e florestas, a zona "pivô" da Eurásia incluía, em suas definiçỗes originais, a ideia de rios caudalosos, enormes jazidas de recursos minerais, do ferro e manganês ao fósforo e o potássio, enormes reservas de recursos energéticos como carvão mineral e petróleo ${ }^{1}$.

1 José Luis Fiori (2011) considera que "Mackinder formulou um novo princípio e uma nova teoria geopolítica, que marcaram a política externa inglesa do século XX. 'Quem controla o coração do mundo comanda a ilha do mundo, e quem controla a ilha do mundo comanda o mundo'. A 'ilha do mundo' seria o continente eurasiano, e o seu 'coração' estaria situado - mais ou menos - entre o Mar Báltico e o Mar Negro, e entre Berlim e Moscou”. 
No início do século passado, existia, naturalmente, uma forte influência das teorias geopolíticas da Europa e dos Estados Unidos nos meios militares sul-americanos. Foram exatamente autores relacionados com a área militar que se dedicaram a estudar a geopolítica da região. No caso específico de nosso trabalho, o mais relevante a destacar é que cerca de vinte anos depois da formulação de Mackinder, o conceito de Heartland passou a ser utilizado também nas análises sobre o território da América do Sul2 ${ }^{2}$. A principal contribuição neste sentido foi o trabalho desenvolvido por Travassos (1935), depois reinterpretado por Tambs (1965). Couto e Silva (1955) e Pinochet (1968) continuaram utilizando os referenciais teóricos existentes, mas aproveitaram-se das contribuições atualizadas pelo geógrafo e geoestrategista holandês Nicholas Spykman33. Os cinco pensadores bolivianos utilizados também agregaram pouco valor teórico à proposta original de Travassos, ainda que representem a visão própria de um país que perdeu quase dois terços do seu território em cinquenta anos, entre 1883 e 1935.

2 De acordo com os bolivianos Baldivieso (1986, p.44) e Francovich (1985, p.96), já no início do século XX, o cientista alemão Alexander Von Humboldt referiu-se ao atual território da Bolívia como "Maciço central dos Andes", "Peru interno" e "promontório da América do Sul".

3 Segundo Fiori (2007), Spykman "partiu das idéias de Halford Mackinder, mas modificou sua tese central. Para Spykman, quem tem o poder mundial não é quem controla diretamente o 'coração do mundo', mas quem é capaz de cercá-lo, como os Estados Unidos fizeram durante toda a Guerra Fria e seguem fazendo até os nossos dias". O Heartland perde importância frente ao rimland. 


\section{2. "Antagonismos geográficos" e "Triângulo estratégico" de Travassos}

A primeira edição do livro de Mario Travassos, de 1930, chamava-se "Aspectos Geográficos Sul-Americanos". Em 1935, o trabalho foi novamente publicado com o nome muito mais audaz de "Projeção Continental do Brasil". De acordo com a interpretação deste autor, exatamente no território da Bolívia ocorria uma série de "antagonismos geográficos com resultantes geopolíticas" relacionados com a sua localização em relação aos três grandes acidentes geológicos da América do Sul: a Cordilheira dos Andes, que divide o continente a leste e a oeste, e as bacias dos rios Amazonas e do Prata, que condicionam uma divisão norte-sul.

De acordo com essa visão, é no território boliviano, na região que entre 1559 e 1825 foi conhecida como "Audiência de Charcas", que se unem as "vertentes" do Oceano Pacífico e do Oceano Atlântico e que se tocam as duas principais bacias hidrográficas da região (MEDEIROS FILHO, 2004, p.10). A Bolívia seria, portanto, o único país da América do Sul a ocupar simultaneamente ou exercer projeção sobre todos esses quatro espaços. As tensões sobre o território boliviano estavam concentradas na área situada entre as cidades de

4 Segundo Baldivieso (1986, p.48), o antagonismo proposto por Travassos "podría decirse que estaba insatisfecho y que había conformado un país vacilante en su triple rol sobre la hoyas amazónica, del Plata y del Pacífico, pero en ninguna de ellas gravitó con la fuerza necesaria para definir sus destinos como nación de estructuras centrípetas. Los internacionalistas y geopolíticos bolivianos, insistentemente, anotan su indudable rol en los tres caminos continentales, pero ocultan, muy comprensiblemente, su debilidad e invertebración que hizo de ella un país vacilante". 
Santa Cruz de La Sierra, Cochabamba e Sucre. Existia entre essas cidades um "triângulo estratégico", que incluía as importantes cidades mineradoras de Oruro e Potosí. Justamente nesta zona, de acordo com Travassos, confrontavam-se abertamente os interesses do Brasil ("influências amazônicas") e da Argentina ("influências platinas") pela supremacia geopolítica do sub-continente. Pfrimer e Roseira (2009, p.6) lembram que, para o militar brasileiro, "a chave desses problemas se encontra no triângulo econômico, verdadeiro signo da riqueza boliviana"s.

Travassos identifica a influência da Argentina, detentora da desembocadura do rio da Prata, como uma ameaça sobre a Bolívia. Desde alguns anos antes, o país vinha criando vias férreas de comunicação com o Oceano Pacífico no sentido leste-oeste (desde Buenos Aires até Santiago do Chile) e no sentido sul-norte (desde Buenos Aires até La Paz e o porto de Arica) ${ }^{6}$. Segundo o autor, a estratégia argentina de estabelecer essas linhas verticais sobre o mapa sul-americano confrontava claramente com a projeção brasileira de criar caminhos no sentido do oeste, buscando permanentemente uma saída para o oceano Pacífico.

5 Vale apontar para o interessante fato de Ernesto Che Guevara ter decidido iniciar a sua guerrilha exatamente no meio do "triângulo estratégico", mesmo contra as orientações do Estado cubano. O argentino insistia que desde a localidade de Vallegrande seria possível projetar a luta armada para os demais países da região. Em 1967, foi capturado e morto por Rangers estadunidenses e pelo exército boliviano.

6 Também foi criado acesso para Assunção, estabelecendo contato com as capitais de três importantes países. 
Para Leonel Itaussu Almeida Mello (1997), Travassos propunha que o Brasil lançasse mão de uma contundente política de comunicações que garantisse a unidade territorial $\mathrm{e}$, ao mesmo tempo, assegurasse a projeção brasileira para a América do Sul. Durante o primeiro governo de Getúlio Vargas, iniciou-se a construção da linha entre Corumbá e Santa Cruz de la Sierra, visando exatamente a ampliar a presença do Brasil na porção oriental do território boliviano. Naquele momento, ainda não existia a atual conexão argentina entre Buenos Aires e Santa Cruz de la Sierra?

Vale comentar que Mackinder usou a ideia de Heartland para falar de uma área mediterrânea central que daria ao Estado que a domina capacidade de mobilidade e projeção em todas as direções da Eurásia. Ao mesmo tempo era uma fortaleza natural. O caso da Bolívia é similar. Uma área mediterrânea central que pode ser considerada uma fortaleza natural; um altiplano entre duas cordilheiras. É uma plataforma de projeção para todas as direções e, ao mesmo tempo, está sujeita a sofrer ameaças desde todas as direções. A grande boliviana questão é a não utilização destas potencialidades pelo Estado.

7 Pfrimer e Roseira (2009, p.11) apontam que “Por pressão argentina e pelas dificuldades de se romper os contrafortes andinos entre Cochabamba e Santa Cruz, construiu-se um ramal ligando Santa Cruz até o departamento de Tarija e daí até o norte argentino. Assim a malha ferroviária oriental boliviana se integra, ainda hoje, à ocidental apenas em território argentino". Ou seja, até os dias atuais não existe um ramal entre Santa Cruz e Cochabamba. 


\section{"Heartland Sul-Americano" de Tambs}

Pfrimer e Roseira (2009, p.7) argumentam que "em momento algum" Travassos se referiu à ideia de Heartland ou Pivô Geográfico da História tal como havia feito Mackinder . Consideram que a responsabilidade pela "reconceitualização dos postulados de Travassos em direção do conceito de Heartland foi proposta pelo professor de História do Brasil na Universidade de Creighton, Lewis Tambs". Este, não Travassos, teria adaptado a ideia de Mackinder para a situação da América do Sul. Assim, para o estadunidense, "quem controla Santa Cruz comanda Charcas. Quem controla Charcas comanda o Heartland. Quem controla o Heartland comanda a América do Sul" (GUMUCIO; WEISE, 1978)?.

8 Afirmam que "talvez a única passagem que tenha sido mal interpretada posteriormente é aquela em que o marechal brasileiro afirmava a força coordenadora do Brasil em direção longitudinal no território sul-americano: 'Em primeiro lugar, as grandes linhas de massa continental - as cumiadas dos Andes dividindo-a em duas vertentes, a vertente de leste trabalha pelos compartimentos de duas imensas bacias - a do Amazonas e a do Prata. Em seguida, o fato dessas duas bacias se encontrarem em uma sorte de pivot, emergindo das formaçôes da Cordilheira - o planalto boliviano - a partir do qual os caudais daquelas bacias se colocam verdadeiramente em antagonismos. O uso da palavra pivot deve ser interpretada no contexto do parágrafo e do livro, nesse sentido ela não faz referência ao Pivô Geográfico da História de Mackinder, mas sim ao fato do planalto boliviano se constituir numa área de ligação entre a Bacia do Prata e Amazônica".

9 Tambs afirma que "a história mostrou a importância dessa região durante os impérios pré-colombianos Aymara e Inca e mais tarde durante a colonização espanhola, quando o altiplano e Charcas eram centros de poder. O Alto Peru permaneceu o centro nervoso do poder espanhol na América do Sul até o final do Império espanhol... O rimland sul-americano cercou Charcas. Sob a falta de liderança boliviana, o Heartland não teria mais força para agir e foi coagido. Vista como a luta pelo Heartland de Charcas, a história sul-americana dos séculos XIX e XX se torna inteligível (Idem, 1978). O autor utiliza o conceito de rimland, de Spykman, de 1942. 
Nota-se que há um limite para a utilização do termo Heartland no caso da América do Sul. Em nossa interpretação, a validade do conceito se restringe a sugerir semelhanças gerais, que perdem sentido quando se busca generalizá-lo amplamente. Uma das grandes características que marca o Heartland sul-americano é a visível ausência de um poder integrador político, econômico e bélico. $\mathrm{O}$ Estado boliviano não assumiu esse caráter. Antes da Guerra do Chaco (1932-1935), as elites governantes da Bolívia fizeram poucos movimentos no sentido de construir vias para integrar o território nacional, consolidar as fronteiras e ocupar as vastas áreas do oriente, consideradas "baldias". Depois da Revolução Nacionalista de 1952, os planos de "marcha para o leste" ganharam amplo apoio, com a construção de infraestrutura de transportes e serviços. O projeto buscava ativar uma linha de polos de desenvolvimento, do altiplano, passando pelos vales e chegando aos llanos de Santa Cruz, promovendo a integração nacional (PFRIMER; ROSEIRA, 2009, p.10). Em 1954, o governo de La Paz construiu uma rodovia entre Cochabamba e Santa Cruz de la Sierra. Naquele momento, a Argentina e o Brasil já estavam unidos à cidade pelas linhas de trem desde Buenos Aires e Santos (DEL BOSCO, 2006, p.4). O geopolítico boliviano Alipio Valencia Vega (2011, p.255) afirma que:

La vastedad territorial de Bolivia, abarcando cuatro regiones tan distintas entre sí y, sobre todo, separadas de otras por accidentes geográficos poderosos, sólo podría mantenerse a condición de que la acción humana de los escasos pobladores de dicho territorio se orientara prácticamente y sin descanso, desde el primer día 
de la independencia, al aprovechamiento efectivo de los principales recursos económicos de esas regiones y a la superación de los obstáculos geográficos, mediante la apertura de vías de penetración de unas regiones sobre otras. Si no se operaba esta acción, los centros nerviosos del país siempre estarían sumamente lejanos de la periferia de las fronteras, las cuales podían ser seccionadas fácilmente por los vecinos, en cuanto fuesen algo más poderosos y se aproximasen en su acción, desde sus costas hasta su propio interior.(VEGA, 2011, p.255).

Veremos a seguir como, anos mais tarde, alguns autores expandiram os "limites originais" do Heartland sul-americano como fruto das descobertas de maiores riquezas ${ }^{10}$. A área passou a incluir o norte argentino, o Paraguai e o centro-oeste brasileiro. Foi o caso dos militares Couto e Silva (1955) e Pinochet (1978), ambos fortemente influenciados pela Doutrina de Segurança Nacional contra o "inimigo vermelho". O Heartland sul-americano ampliado, riquíssimo em rios, gás natural, petróleo, minérios e terras férteis passou a ser também identificado como estratégico para a segurança regional e vital para o processo de integração sul-americana.

10 Com o objetivo de definir uma abrangência física ao conceito de Heartland sul-americano, Oliveira e Garcia (2010, p.10) elaboraram um mapa azimutal equidistante centrado na fronteira entre o Brasil e a Bolívia. A figura mostra as principais cidades sul-americanas com mais de 500 mil habitantes. A partir do ponto central, em um raio de 2300 quilômetros, encontram-se as principais cidades do Cone Sul e dentro de um raio de 3100 quilômetros, estão todas as maiores cidades da América do Sul. 
Em 1981, o general brasileiro Golbery do Couto e Silva apresentou a ideia de que na configuração geopolítica da América do Sul existiam cinco áreas continentais. No caso de nosso estudo, o mais pertinente é fazer referência à "Área Geopolítica Continental de Soldadura”, integrada pelo Paraguai, a Bolívia e os estados brasileiros de Mato Grosso e Rondônia (FREITAS, 2004, p.49-50). É interessante destacar que dez anos antes, em 1946, no livro "Una obra y un destino", o boliviano Alberto Ostria Gutierrez já havia falado em termos muito parecidos e inclusive utilizado a expressão "soldadura".

Outro destacado pensador boliviano, Jaime Mendoza, realizou trabalhos que resgataram a identidade nacional e enalteceram a nacionalidade. Seu livro "El macizo boliviano", de 1935, teve grande influência ao desenvolver ideias nativistas que relacionavam o território retalhado com a fortaleza cultural do país. O intelectual descreveu o maciço desta maneira:

Hemos llamado Macizo de Charcas y por extensión Macizo Boliviano, a esa formidable expansión geográfica de los Andes sudamericanos que se halla en la parte céntrica de su recorrido de más de cuatro mil kilómetros por las costas del Pacífico.

11 Segundo este autor, "situada en el centro de la América Meridional, cabecera de los tres grandes sistemas hidrográficos - Amazonas, Plata y Pacífico - nexo entre dos océanos, limítrofe de cinco naciones, obligado paso de norte a sur y de este a oeste, la geografía impone a Bolivia, no una función aisladora y de aislamiento, sino de atracción, de articulación, de unión, de soldadura entre los países que le rodean”. 
De ella dijimos que constituye el eslabón más grueso y pujante de cuantos integran la cadena andina, dilatándose al oriente hacia el corazón de Sudamérica, cual si quiera darse de mano con el macizo del Brasil. (MENDONZA, 1935).

\section{O general Pinochet (1978), bastante influenciado pelas ideias de Golbery, descreve a região da seguinte maneira:}

Pela sua situação relativa na América do Sul não tem função isoladora, mas, ao contrário, de atração, articulação e soldadura entre os países que a rodeiam. Pela sua configuração, poderia ser comparada a um gigantesco imã que une as peças do conjunto e que se deixasse de atuar desmoronaria desarticulando-se ${ }^{12}$.

\section{Três conflitos, três derrotas}

Os três conflitos bélicos enfrentados pela Bolívia resultaram em significativas perdas territoriais. No momento de sua criação, em 1825, o país tinha um território três vezes maior que os atuais 1,09 milhão de quilômetros quadrados.

12 Pinochet concebe o Estado como um "organismo formado por Territorio o espacio, Población o masa humana y Soberanía. Estos adquieren una constitución semejante a una ameba en el que se distinguen: las fronteras o capa envolvente cuya resistencia está de acuerdo con el grado de potencialidad del núcleo vital, el 'Heartland', las comunicaciones y el Ciclo vital del Estado, que está demostrado por la historia de la humanidad en el transcurso de los siglos: nacer, desarrollarse y morir". 
A situação foi totalmente alterada pela Guerra do Pacífico contra o Chile, a Questão do Acre contra o Brasil e a Guerra do Chaco contra o Paraguai. Ainda que a interpretação das razões e do desenrolar desses choques armados seja bastante complexa, podemos apontar dois fatores como os determinantes: a desatenção do Estado boliviano com as fronteiras distantes das principais cidades e a participação de empresas estrangeiras no centro dos embates ${ }^{13}$.

Na Guerra do Pacífico (1879-1883), a Bolívia perdeu a sua única saída para o mar. Em 1825, com a independência boliviana, as autoridades chilenas haviam reconhecido (aceitado) os limites entre os dois países. No entanto, por volta de 1830, surgiu um novo elemento como detonador do conflito: as descobertas no litoral da Bolívia de imensas reservas de guano, nome dado às fezes de aves e morcegos acumuladas sobre as pedras. Devido aos grandes conteúdos de nitrogênio, fosfatos e amoníaco, o material era amplamente utilizado como fertilizante no empobrecido solo da Europa. O surgimento da química agrícola e a maior intervenção sobre as terras pobres alavancaram os preços internacionais dos fertilizantes. Posteriormente também foram identificadas, na região, imensas concentrações de salitre, outro tipo de adubo. A partir de então, as províncias de Tarapacá e Antofagasta e o deserto de Atacama ganharam relevância. Centenas de quilômetros de ferrovias passaram a conectar os portos bolivianos, de Antofagasta, com a cidade de Oruro, passando por Uyuni, no departamento de Potosí.

13 Reyes (2010) apresenta uma análise atual e detalhada dos três conflitos. 
Os autores bolivianos analisados associam o estouro da guerra com os movimentos de empresas anglo-chilenas para apoderar-se de uma área rica, despovoada e praticamente abandonada pelo Estado boliviano. Por outro lado, alguns documentos chilenos, como o de Liberona (2002), atribuem o conflito ao fato do país discordar dos limites territoriais determinados de forma "arbitrária" pelo marechal Antonio José de Sucre, em 1825. O citado autor faz referência à ordem expressa de Simón Bolívar para Sucre: "dar un puerto para Bolivia a cualquier costo"14.

A Questão do Acre (1902-1903) também é bastante intricada. De acordo com o general brasileiro Carlos de Meira Mattos (1980), os antecedentes do conflito estão presentes nas contendas sobre a navegabilidade nos rios fronteiriços entre o Brasil e a Bolívia. Desde 1826, os sucessivos governos brasileiros rechaçaram inúmeras propostas apresentadas por bolivianos e estadunidenses para autorizar a navegação de embarcações estrangeiras em águas interiores do território brasileiro.

Na prática, entretanto, a eclosão do enfrentamento coincidiu com o surto da borracha. $\mathrm{O}$ foco estava nas seringueiras,

14 "Tarapacá foi cedida em caráter definitivo ao Chile, que ainda recebeu a posse temporária de Tacna e Arica - acerca das quais desenvolveu-se uma longa disputa diplomática que somente veio a ser resolvida em 1929. Os últimos soldados chilenos deixaram o Peru em agosto de 1884 . O armistício com a Bolívia (abril de 1884) permitiu ao Chile continuar no controle do Atacama até a negociação de um acordo de paz definitivo, que somente se materializou em 1904" (COLLIER apud REYES, 2010, p.56). Até os dias atuais, a Bolívia move judicialmente demandas para retomada de sua saída para o mar, mantendo a sua pequena frota estacionada no Lago Titicaca. 
de cujo látex se produzia a borracha cada vez mais utilizada pela nascente indústria automobilística dos Estados Unidos e da Europa. Incapaz de defender as suas remotas províncias do nordeste, a Bolívia optou, com o apoio do governo dos Estados Unidos, por transferir o controle da região ao AngloBolivian Syndicate de Nova Iorque. O "Sindicato" assumiu o controle efetivo sobre o Acre, com o monopólio de exploração da borracha na área e amplos poderes para administrar, arrecadar impostos e organizar polícias. A empresa tinha como principal executivo um primo do presidente estadunidense Theodore Roosevelt e como um dos maiores acionistas o banqueiro inglês Rothschild.

As tensões com o governo brasileiro foram crescentes até a assinatura do Tratado de Petrópolis, em 1903, no qual a Bolívia abriu mão do território do Acre. Como contrapartida, o Brasil ofereceu dois milhões de libras esterlinas e a proposta de construir a ferrovia Madeira-Mamoré, que possibilitaria uma saída boliviana pelo oceano Atlântico via Belém do Pará (REYES, 2010, p.61-62).

Desde os tempos coloniais, a região do Chaco sempre recebeu pouca atenção e era caracterizada por imprecisões na demarcação das fronteiras. A Guerra do Chaco (19321935) colocou frente a frente os dois países mais pobres da América do Sul, que lutaram de forma cruel por uma porção de terra inóspita, seca, arenosa e despovoada. Alguns autores, como Chiavenato (1980), relacionam o conflito com as descobertas de jazidas de petróleo no Chaco, por volta dos anos 1920. Como na Bolívia as explorações eram feitas pela estadunidense Standard Oil, enquanto no Paraguai os trabalhos estavam a cargo da inglesa Shell, a guerra seria resultado dos interesses dessas petrolíferas. 
No entanto, outros autores, como Gumucio (1978), interpretam que o enfrentamento teve suas origens em motivos mais estruturais. É necessário tomar em conta a conjuntura de crise dos anos 1930, a queda das exportações bolivianas de estanho e a sublevação que tomou conta do país. Além disso, para a Bolívia, depois de perder a saída para o Pacífico, a relevância do Chaco estava na possibilidade de garantir uma saída para o Atlântico pela via dos rios Paraguai e da Prata. Em poucos dias, a tentativa boliviana de obter rapidamente o controle de portos no Rio Paraguai se transformou em uma terrível empreitada.

Gutierrez (1946) considera que com o término da Guerra do Chaco fechou-se para a Bolívia uma etapa da vida nacional. Acabou-se o processo de configuração territorial e foram estabelecidos os limites internacionais do país. De acordo com o autor, "estaban terminados los pleitos fronterizos con todos los vecinos, bien o mal, justa o injustamente, por la razón o por la fuerza, habían sido trazadas todas sus fronteras y suscritos los convenios respectivos" 15 .

15 Vega (2011, p.257) considera que "Las mayores pérdidas territoriales de Bolivia no fueron realizadas por la vía diplomática, sino que fueron consecuencias de diversas guerras o 'revoluciones' sostenidas con los países vecinos. Diplomáticamente se perdieron parte del territorio del Litoral [no el propio litoral, sino un pedazo de la provincia del Litoral] cedido a Chile en 1866 y los territorios cedidos a Brasil en el norte y el oriente en 1867, también más tarde el territorio de Bermejo y la Puna de Atacama cedidos a Argentina por el tratado de 1889. Igualmente, la zona de Tambopata al Perú en 1909. Todos los demás territorios, o sea el Litoral sobre el Océano Pacífico, el Acre y el Chaco fueron perdidos como consecuencia de guerras que sostuvo Bolivia con los países vecinos: Chile, el Brasil y el Paraguay. En el fondo de estas guerras que aparecen en sus causas como esencialmente políticas, hay una influencia 


\section{0 “triângulo estratégico" hoje}

As medidas promovidas pelo Estado boliviano depois da Guerra do Chaco tiveram impacto visível sobre o ordenamento territorial do país. A nova rede de caminhos e estradas possibilitou a migração e estimulou o surgimento de novas cidades. Além disso, pode-se afirmar que um dos principais resultados da "competição" brasileira e argentina pelo controle de Charcas foi o progressivo fortalecimento do oriente boliviano, através de investimentos, estímulos financeiros, construção de infraestrutura e estabelecimento de uma maior oferta de serviços públicos. O triângulo estratégico proposto por Travassos foi alterado ${ }^{16}$.

económica poderosa. Se producen esos conflictos armados por la codicia de la riquezas naturales existentes en los territorios disputados por las armas; riquezas naturales que son materias primas altamente apreciadas en los mercados del mundo".

16 Del Bosco (2006, p.6), fazendo referência a Travassos, afirma que "si tuviéramos que actualizar su pensamiento respecto a Bolivia, dejaríamos de lado el triángulo Sucre-Cochabamba-Santa Cruz de la Sierra y hablaríamos a futuro de un eje sur-norte, conformado por los departamentos de Tarija y Santa Cruz de la Sierra. El primero con la segunda reserva de gas en América del Sur, eje con capacidad para proyectarse exteriormente. Tarija gracias al impulso de los hidrocarburos es el departamento que más ha crecido. Durante el período 1988-2004 su PBI se incrementó en 191\%". Por sua vez, Pfrimer e Roseira (Op.cit., p.12-15) consideram que "A influência dos discursos geopolíticos brasileiro e argentino, principalmente no que concerne o conceito de triângulo estratégico boliviano, sobre suas políticas territoriais, acabou ao longo dessa disputa materializando em solo boliviano um triângulo. Não aquele representado por Travassos, uma vez que Sucre deixou de ser a capital política do país e tem perdido cada vez mais sua importância econômica. Ademais, a expansão econômica de Tarija, após a descoberta das importantes reservas de gás e petróleo, a colocou como um dos quatro principais centros urbanos 
Santa Cruz de la Sierra, de pequena vila jesuítica estabelecida em 1561 ao pé da cordilheira de Cochabamba, transformou-se rapidamente em um importante centro de articulação continental e em motor econômico da Bolívia ${ }^{17}$. Graças à intensa integração com o Brasil em diversos setores, como o agrícola e o energético, a zona já é interpretada como uma macro-região associada ao estado de Mato Grosso. Santa Cruz e o oriente boliviano contam com os privilégios de localização disponíveis ao Heartland. A região tem relações tanto com o Pacífico como com o Atlântico, potencializadas pelos

do país. Essa área com o formato triangular é constituída por uma rede urbana de três cidades principais: Santa Cruz, Cochabamba e Tarija. Envoltos e bem articulados a esses centros urbanos principais há ainda centros secundários como Potosí, Oruro, Sucre e Yacuiba... Esse novo arranjo territorial detém aproximadamente $60 \%$ do Produto Interno Boliviano, quase metade da população boliviana e $98 \%$ e $99,2 \%$ das reservas provadas de gás e petróleo na Bolívia, respectivamente". Tomando em conta os projetos de corredores bioceânicos que passam pelos países andinos, acredita-se que a área do novo triângulo possa constituir-se no futuro Hub Logístico Sul-Americano.

17 Existem boas rodovias que conectam Santa Cruz com Cochabamba, La Paz e os portos do Peru (Matarani e Ilo) e do Chile (Arica e Antofagasta). Igualmente, há oferta para o leste até Corumbá e os portos do Rio Paraguai (um canal liga Puerto Aguirre, Puerto Quijarro e Puerto Suárez à Hidrovia Paraguai-Paraná, na fronteira com o Brasil). Nos últimos anos, tem avançado o projeto de ativação do Puerto Busch, localizado na fronteira boliviana com o Paraguai. Este é o chamado "Mar guarani", que permitirá um acesso direto da Bolívia ao oceano Atlântico via rio Paraguai, sem a necessidade de navegar pelo canal de Tamengo. O novo caminho permitirá intensificar os investimentos em atividades como petróleo, gás, ferro das minas de Mutún e a produção agrícola. As redes ferroviárias já integram Santa Cruz com o Atlântico (até Santos e Buenos Aires) e quase até o Pacífico. Há planos de ligar a região com o sistema amazônico, até Porto Velho, Manaus e Santarém. 
projetos da iniciativa para a Integração da Infraestrutura SulAmericana (IIRSA) ${ }^{18}$. Somente na Bolívia, são 53 obras de infraestrutura em marcha, como ferrovias, hidrovias, rodovias, sistemas intermodais, energia e fibra ótica ${ }^{19}$.

A tendência é que ganhe força uma visão global de planejamento e organização para a integração regional sob critérios políticos e estratégicos, e não mais pelo simples estímulo do mercado ou das empresas privadas. A integração de infraestrutura, agora dirigida pela UNASUL, poderia articular a integração física com os esforços de ampliar o comércio intrarregional e de expandir a complementação das cadeias produtivas. Neste novo contexto, a importância do território

18 A IIRSA foi criada em 1990 sob a orientação do "Regionalismo Aberto" da CEPAL e do "Novo Regionalismo" do BID. A iniciativa funcionaria como a espinha dorsal da proposta estadunidense de anexação continental, a chamada Área de Livre Comércio das Américas (ALCA). A proposta da IIRSA, que continuou existindo apesar do enterro da ALCA em Mar del Plata, em 2005, se concentrou no fortalecimento de "corredores de exportação", aprofundando ainda mais a condição de nossos países como vendedores de mercadorias de baixo valor agregado para os centros industriais. A mudança atual está na criação do Conselho de Infraestrutura e Planejamento (Cosiplan) dentro da União de Nações Sul-Americanas (UNASUL). Desta forma, os governos assumiram a direção do processo e a tendência é intensificar as obras orientadas para a efetiva integração regional em energia, transportes e comunicações. Entende-se como essencial que os Estados nacionais e as populações fortaleçam o seu poder de intervenção nos projetos.

19 Del Bosco (2006, p.5) aponta que "hoy Santa Cruz, además de petróleo, madera, caña de azúcar y ganadería, ha desarrollado el cultivo la soja y ha pasado a constituirse en un centro de importantes inversiones de agricultores argentinos y brasileños. Su PBI representa el 30\% del total de Bolivia, la actividad agropecuaria el 43\%, la del comercio el 36,2\% y la industria manufacturera el 35\%. Por su parte sus bancos acaparan el mayor movimiento financiero del país". 
boliviano só tende a aumentar. Seja com um novo triângulo estratégico (Santa Cruz, Cochabamba e Tarija) ou junto ao Paraguai e ao Centro-Oeste do Brasil, a Bolívia continuará tendo uma função crucial neste processo, como a grande "área de soldadura”. De acordo com Padula (2011), esses espaços mediterrâneos, situados no coração continental sul-americano, "ao mesmo tempo em que sofrem com o confinamento do interior, sua posição lhes aufere enorme potencial para exercer o papel de plataforma de interligação do comércio regional e bioceânico".

\section{Referências}

BALDIVIESO, Valentin Abecia. Las relaciones internacionales en la historia de Bolivia. Tomo III. Editorial Los Amigos del Libro, Cochabamba, 1986.

CHIAVENATO, José Julio. A guerra do Chaco (leia-se petróleo). São Paulo: Brasiliense, 1980.

COUTO E SILVA, Golbery do. Conjuntura Política Nacional, O Poder Executivo e a Geopolítica do Brasil. Rio de Janeiro: José Olympio Editora, 1981.

. Geopolítica do Brasil. Rio de Janeiro: Livraria José Olympio, 1955.

DEL BOSCO, Guillermo Travassos. Santa Cruz de la Sierra y la Política Exterior Argentina. Centro Argentino de Estudios Internacionales. Programa Política Exterior Argentina, 2006._www.caei.com.ar 
MEDEIROS FILHO, Oscar. Da confrontação à cooperação: as alterações geopolíticas na América do Sul, 2004.

FIORI, José Luís. Nicholas Spykman e a América Latina. Le Monde Diplomatique Brasil, 24/11/2007.

FRANCOVICH, Guillermo. El pensamiento boliviano en el siglo XX. Cochabamba: Los Amigos del Libro, 1985.

FREITAS, Jorge Manoel da Costa. A escola geopolítica brasileira. Rio de Janeiro: BIBLIEX, 2004.

GUMUCIO, Mariano Baptista; WEISE, Agustín Saavedra. Antología Geopolítica en Bolivia. Cochabamba: Los Amigos del Libro, 1978.

LEWIS, Paul H. O Paraguai da Guerra da Tríplice Aliança à Guerra do Chaco. In: BETHELL, Leslie (org.). História da América Latina: de 1870 a 1930, São Paulo: Edusp, 2008, volume V.

LIBERONA, Javier Sánchez. Mediterraneidad de Bolivia. Efectos geopolíticos de una eventual salida al Pacífico. Revista de la Marina de Chile, 2002.

MELLO, Leonel Itaussu de Almeida. Quem tem medo da Geopolítica? São Paulo: Edusp, 1999.

- Geopolítica do Brasil e a Bacia do Prata. Manaus:

Universidade Federal do Amazonas, 1997. 
MENDOZA, Jaime. El macizo boliviano. La Paz: Imp. Arnó Hnos, 1935, p. 277.

OLIVEIRA, Lucas K.; GARCÍA, Tatiana de Souza L. O conceito de Heartland na geopolítica clássica: funcionalidade e limites para a análise da Região central da América do Sul. V Encontro Nacional da ANPPAS, Florianópolis, outubro 2010.

PADULA, Raphael. Infraestrutura, geopolítica e desenvolvimento na integração sul-americana: uma visão crítica à IIRSA. Laboratório de Estudos da América Latina (LEAL), 2011.

PINOCHET, Augusto. Geopolítica de Chile. Buenos Aires: El Cid, 1978.

PFRIMER, Matheus Hoffmann; ROSEIRA, Antônio Marcos. Transformações territoriais na Bolívia: um novo "triangulo estratégico"?. In: ENCUENTRO DE GEÓGRAFOS DE AMÉRICA LATINA, 12, 2009 Montevideo.Anais... Montevideo, 2009.

PFRIMER, Matheus Hoffmann. Heartland Sul-americano? Dos discursos geopolíticos à territorialização de um novo triângulo estratégico boliviano. GEOUSP - Espaço e Tempo, São Paulo, n. 29, p. 131 - 144, 2011. Disponível em: 225-527-1-pB.pdf - Adobe Reader. 
REYES, Fernando Siliano. O papel das vias de circulação na coesão territorial do Estado boliviano: da audiência de Charcas à Bolívia de 1971. Dissertação ao Programa de PósGraduação em Geografia Humana da USP, 2010.

TAMBS, Lewis (1965). Fatores em America Latina. In: GUMUCIO, Mariano Baptista; WEISE, Agustín Saavedra. Antologia Geopolitica en Bolívia. Cochabamba: Ed. Los Amigos del Libro, 1978, p. 229-244.

TRAVASSOS, Mário. Projeção continental do Brasil. São Paulo: Companhia Editora Nacional, 1935. 